\title{
Correlation of Blood Lactate and Mixed Venous Oxygen Saturation in Off-Pump CABG
}

\author{
Ganapathy Sambandam Kamalakkannan, Ranjith Karthekeyan*, Mahesh Vakamudi, \\ Sandeep Bangale, Rajeshkumar Kodali, Hemanand Nayagam, Sushma Nandipati \\ Department of Anesthesiology, Sri Ramachandra Medical College and Research Institute, Chennai, India \\ Email: ${ }^{*}$ ranjithb73@gmail.com
}

Received 23 May 2014; revised 23 June 2014; accepted 15 July 2014

Copyright (C) 2014 by authors and Scientific Research Publishing Inc.

This work is licensed under the Creative Commons Attribution International License (CC BY).

http://creativecommons.org/licenses/by/4.0/

c) (i) Open Access

\begin{abstract}
Aim: To evaluate the correlation of blood lactate and mixed venous oxygen saturation to predict outcome in off-pump coronary artery bypass grafting. Method: This is a randomized study including 30 patients. Blood lactate and mixed venous oxygen saturation were measured in 4 groups of patients-number of grafts, presence or absence of left main coronary artery disease, ejection fraction and serum creatinine. Blood samples were taken before induction, after grafting, on intensive care unit admission, 24 hours and 48 hours after surgery. The measured blood lactate and mixed venous oxygen saturation are compared to assess the outcomes in terms of duration of ventilation and intensive care unit stay. Results: The blood lactate and mixed venous oxygen saturation values increased post operatively but no statistically significant difference in three groupsnumber of grafts, left main coronary artery disease and ejection fraction. In serum creatinine group, the blood lactate value was found to be statistically significant after grafting in patients with creatinine $<1.5 \mathrm{mg} / \mathrm{dl}$, however, there was a significant disparity in numbers. Conclusion: Mixed venous oxygen saturation is a better predictor of morbidity than blood lactate in terms of intensive care unit stay in patients undergoing off pump coronary artery bypass grafting.
\end{abstract}

\section{Keywords}

Off-Pump Coronary Artery Bypass Grafting, Blood Lactate, Mixed Venous Oxygen Saturation, Ejection Fraction, Duration of Ventilation, Duration of Intensive Care Unit Stay

\section{Introduction}

Coronary artery disease is surgically treated by grafting the coronary arteries with different native vessels. Coronary artery bypass grafting was traditionally performed by using cardiopulmonary bypass. Only in the last few

*Corresponding author.

How to cite this paper: Kamalakkannan, G.S., Karthekeyan, R., Vakamudi, M., Bangale, S., Kodali, R., Nayagam, H. and Nandipati, S. (2014) Correlation of Blood Lactate and Mixed Venous Oxygen Saturation in Off-Pump CABG. World Journal of Cardiovascular Surgery, 4, 131-138. http://dx.doi.org/10.4236/wjcs.2014.47020 
decades, off-pump coronary artery bypass grafting surgery has come into clinical practice allowing the same surgery to be performed without the use of cardiopulmonary bypass. The avoidance of cardiopulmonary bypass has been proposed to reduce the postoperative systemic inflammatory response in off-pump coronary artery bypass grafting (OPCAB). Blood lactate and mixed venous oxygen saturation are different indices of adequacy of oxygen delivery to the tissues. Studies have shown that high blood lactate levels and low mixed venous oxygen saturation during coronary artery bypass grafting are potential early predictors of morbidity and mortality [1] [2].

Hypothesis: Blood lactate level and mixed venous oxygen saturation predict the morbidity in patients undergoing off pump coronary artery bypass grafting.

Our aim is to evaluate the correlation of blood lactate value and the mixed venous oxygen saturation in predicting outcome in off pump coronary artery bypass grafting.

\section{Method}

30 consecutive patients who underwent off pump coronary artery bypass grafting were included in this randomized prospective study. The hospital ethics committee approval was obtained. All the patients underwent surgery under general anesthesia with endotracheal intubation and controlled ventilation. Anesthesia was administered as per our institutional practice. Standard monitoring was used which includes electrocardiogram, invasive artery pressure, pulse oximetry, end-tidal carbondioxide, pulmonary artery pressure, temperature, urine output and bispectral index. Coronary artery bypass grafting was performed off pump by stabilizing the heart with octopus suction (Maquet) apparatus while grafting. Left internal mammary artery was used for grafting left anterior descending artery and other arteries were grafted using saphenous vein grafts.

Blood lactate levels and mixed venous oxygen saturation are measured serially by taking blood samples at baseline after placement of pulmonary artery catheter, after grafting and on admission of patients to intensive care unit. Day 1 sample taken after 24 hours and day 2 sample after 48 hrs were also studied. Blood lactate and mixed venous oxygen saturation values are obtained from standard blood gas analysis (ABL 800 Basic).

Blood lactate and mixed venous oxygen saturation values were compared in four groups of patients, divided depending on presence or absence of left main coronary artery disease, ejection fraction $\leq 45 \%$ or $>45 \%$, creatinine $\leq 1.5 \mathrm{mg} / \mathrm{dl}$ or $>1.5 \mathrm{mg} / \mathrm{dl}$ and number of grafts $\leq 3$ or $>3$. The effect of blood lactate and mixed venous oxygen saturation on duration of ventilation and intensive care unit stay were also studied.

\section{Statistics}

Continuous variables are represented as mean \pm standard deviation. Student's t-test was used when appropriate for comparison of continuous variables. Association of independent variables with the outcome measurements of duration of ventilation and duration of intensive care unit stay were explored by using a logistic regression analysis. The data were analyzed using IBM.SPSS.19.0 version.

\section{Results}

\subsection{Left Main Coronary Artery Disease}

The number of patients with left main coronary artery disease was 11 and without left main coronary artery disease were 19. Blood lactate values were similar in both the subsets. The blood lactate level was highest in the sample sent on day one in patients with left main disease $(2.281 \mathrm{mmol} / \mathrm{L})$ and was highest on intensive care unit admission in patients without left main disease $(2.742 \mathrm{mmol} / \mathrm{L})$ and decreased thereafter. Mixed venous oxygen saturation after grafting was higher in patients with left main coronary artery involvement compared to those without left main disease. Mixed venous oxygen saturation was lowest in the sample sent on day two in both the subsets (59.50\% \& 60.28\%). There was no statistically significant difference between the two subsets in terms of blood lactate and mixed venous oxygen saturation (Table 1).

\subsection{Ejection Fraction}

The number of patients with ejection fraction $\leq 45 \%$ were 12 and with ejection fraction $>45 \%$ were 18 . The blood lactate values increased after surgery when compared to baseline values. Blood lactate values were slightly 
Table 1. Comparison of blood lactate and mixed venous oxygen saturation levels in patients with and without left main coronary artery involvement.

\begin{tabular}{|c|c|c|c|c|}
\hline & & With left main $(n=11)$ & Without left main $(n=19)$ & $\mathrm{p}$ value \\
\hline \multirow{2}{*}{ Baseline } & Blood lactate & 0.881 & 1.236 & 0.061 \\
\hline & $\mathrm{SvO}_{2}$ & 75.209 & 74.621 & 0.773 \\
\hline \multirow{2}{*}{ After grafting } & Blood lactate & 1.563 & 1.831 & 0.272 \\
\hline & $\mathrm{SvO}_{2}$ & 76.781 & 72.515 & 0.266 \\
\hline \multirow{2}{*}{ ICU admission } & Blood lactate & 2.236 & 2.742 & 0.177 \\
\hline & $\mathrm{SvO}_{2}$ & 71.154 & 71.268 & 0.974 \\
\hline \multirow{2}{*}{ Day 1} & Blood lactate & 2.281 & 2.052 & 0.547 \\
\hline & $\mathrm{SvO}_{2}$ & 65.063 & 67.889 & 0.351 \\
\hline \multirow{2}{*}{ Day 2} & Blood lactate & 1.500 & 1.594 & 0.638 \\
\hline & $\mathrm{SvO}_{2}$ & 59.500 & 60.284 & 0.701 \\
\hline
\end{tabular}

ICU—Intensive care unit; $\mathrm{SvO}_{2}$ — Mixed venous oxygen saturation; $\mathrm{p}$ value $<0.05$ is significant.

higher in patients with ejection fraction $>45 \%$ than with ejection fraction $\leq 45 \%$, except in day one sample. The lactate level was highest in the sample sent on intensive care unit admission in both the subsets ( $2.35 \mathrm{mmol} / \mathrm{L} \&$ $2.69 \mathrm{mmol} / \mathrm{L}$ ). Mixed venous oxygen saturation values show a decreasing trend in both the subsets after surgery. However the mixed venous oxygen saturation was higher in patients with ejection $>45 \%$. Mixed venous oxygen saturation were lowest in the sample sent on day two in both the subsets (59.9\% \& 60.0\%). There was no statistically significant difference between the two subsets in terms of blood lactate and mixed venous oxygen saturation (Table 2).

\subsection{Serum Creatinine}

The number of patients having serum creatinine $\leq 1.5 \mathrm{mg} / \mathrm{dl}$ were 27 and with creatinine $>1.5 \mathrm{mg} / \mathrm{dl}$ were 3 . The lactate levels were highest in the sample sent on intensive care unit admission in both the subsets $(2.588 \mathrm{mmol} / \mathrm{L}$ \& $2.266 \mathrm{mmol} / \mathrm{L})$. Mixed venous oxygen saturation values show a decreasing trend in both the subsets after surgery. Mixed venous oxygen saturation was lowest in the sample sent on day two in both the subsets (60.12\% \& 58.86\%). There was statistically significant difference between the two subsets in blood lactate values, taken after grafting $(\mathrm{p}=0.031)$ and no statistically significant difference in mixed venous oxygen saturation among two subsets (Table 3 ).

\subsection{Number of Grafts}

The number of patients with $>3$ grafts were 11 and the patients with $<3$ grafts were 19 . In patients with $>3$ grafts the blood lactate values increased after surgery when compared to baseline values except on day 2. Blood lactate level was highest in the sample sent on intensive care unit admission in both the subsets (3.0 mmol/L \& 2.29 $\mathrm{mmol} / \mathrm{L}$ ). Mixed venous oxygen saturation values showed a decreasing trend in both the subsets after surgery. Mixed venous oxygen saturation values were higher in patients with $>3$ grafts except in sample sent on intensive care unit admission. There was no statistically significant difference between the two subsets in terms of lactate and mixed venous oxygen saturation (Table 4).

The outcome of patients was measured in terms of duration of ventilation and intensive care unit stay. The number of patients with blood lactate value on intensive care unit admission $\leq 3 \mathrm{mmol} / \mathrm{L}$ were 24 and $>3 \mathrm{mmol} / \mathrm{L}$ were 6 . Duration of ventilation and intensive care unit stay were almost similar in both the subsets (Table 5). The number of patients with mixed venous oxygen saturation $>65 \%$ were 22 and $\leq 65 \%$ were 8 . The duration of ventilation was similar in both the groups. However the duration of intensive care unit stay was higher when the mixed venous oxygen saturation was $\leq 65 \%$ and is statistically significant $(p=0.029$ ).

Left main artery involvement, ejection fraction \& number of grafts did not affect the duration of ventilation 
Table 2. Comparison of blood lactate and mixed venous oxygen saturation levels in patients with ejection fraction $\leq 45 \%$ and $>45 \%$.

\begin{tabular}{|c|c|c|c|c|}
\hline & & $E F \leq 45 \%(n=12)$ & $\mathrm{EF}>45 \%(\mathrm{n}=18)$ & $\mathrm{p}$ value \\
\hline \multirow{2}{*}{ Baseline } & Blood lactate & 0.908 & 1.239 & 0.086 \\
\hline & $\mathrm{SvO}_{2}$ & 74.842 & 74.833 & 0.997 \\
\hline \multirow{2}{*}{ After grafting } & Blood lactate & 1.675 & 1.772 & 0.675 \\
\hline & $\mathrm{SvO}_{2}$ & 73.092 & 74.739 & 0.665 \\
\hline \multirow{2}{*}{ ICU admission } & Blood lactate & 2.350 & 2.694 & 0.328 \\
\hline & $\mathrm{SvO}_{2}$ & 69.233 & 72.556 & 0.311 \\
\hline \multirow{2}{*}{ Day 1} & Blood lactate & 2.158 & 2.122 & 0.923 \\
\hline & $\mathrm{SvO}_{2}$ & 63.958 & 68.783 & 0.088 \\
\hline \multirow{2}{*}{ Day 2} & Blood lactate & 1.425 & 1.650 & 0.235 \\
\hline & $\mathrm{SvO}_{2}$ & 59.983 & 60.006 & 0.992 \\
\hline
\end{tabular}

ICU—Intensive care unit; EF-Ejection fraction; $\mathrm{SvO}_{2}$ —Mixed venous oxygen saturation; $\mathrm{p}$ value $<0.05$ is significant.

Table 3. Comparison of blood lactate and mixed venous oxygen saturation levels in patients with creatinine $\leq 1.5 \mathrm{mg} / \mathrm{dl}$ and creatinine $>1.5 \mathrm{mg} / \mathrm{dl}$.

\begin{tabular}{|c|c|c|c|c|}
\hline & & Creatinine $\leq 1.5 \mathrm{mg} / \mathrm{dl}(\mathrm{n}=27)$ & Creatinine $>1.5 \mathrm{mg} / \mathrm{dl}(\mathrm{n}=3)$ & $\mathrm{p}$ value \\
\hline \multirow{2}{*}{ Baseline } & Blood lactate & 1.111 & 1.066 & 0.811 \\
\hline & $\mathrm{SvO}_{2}$ & 75.337 & 70.333 & 0.118 \\
\hline \multirow{2}{*}{ After grafting } & Blood lactate & 1.766 & 1.433 & $0.031 *$ \\
\hline & $\mathrm{SvO}_{2}$ & 74.314 & 71.966 & 0.706 \\
\hline \multirow{2}{*}{ ICU admission } & Blood lactate & 2.588 & 2.266 & 0.490 \\
\hline & $\mathrm{SvO}_{2}$ & 71.825 & 65.833 & 0.136 \\
\hline \multirow{2}{*}{ Day 1} & Blood lactate & 2.163 & 1.900 & 0.343 \\
\hline & $\mathrm{SvO}_{2}$ & 67.077 & 64.833 & 0.647 \\
\hline \multirow{2}{*}{ Day 2} & Blood lactate & 1.540 & 1.733 & 0.272 \\
\hline & $\mathrm{SvO}_{2}$ & 60.122 & 58.866 & 0.733 \\
\hline
\end{tabular}

ICU—Intensive care unit; $\mathrm{SvO}_{2}$ —Mixed venous oxygen saturation; *—p value $<0.05$ significant.

Table 4. Comparison of blood lactate and mixed venous oxygen saturation levels in patients with $\leq 3$ grafts and $>3$ grafts.

\begin{tabular}{|c|c|c|c|c|}
\hline & & Number of grafts $\leq 3(n=19)$ & Number of grafts $>3(n=11)$ & $\mathrm{p}$ value \\
\hline \multirow{2}{*}{ Baseline } & Blood lactate & 1.042 & 1.218 & 0.434 \\
\hline & $\mathrm{SvO}_{2}$ & 74.289 & 75.781 & 0.462 \\
\hline \multirow{2}{*}{ After grafting } & Blood lactate & 1.715 & 1.763 & 0.848 \\
\hline & $\mathrm{SvO}_{2}$ & 73.642 & 74.836 & 0.733 \\
\hline \multirow{2}{*}{ ICU admission } & Blood lactate & 2.294 & 3.009 & 0.052 \\
\hline & $\mathrm{SvO}_{2}$ & 71.942 & 69.990 & 0.575 \\
\hline \multirow{2}{*}{ Day 1} & Blood lactate & 2.068 & 2.254 & 0.625 \\
\hline & $\mathrm{SvO}_{2}$ & 67.031 & 66.545 & 0.874 \\
\hline \multirow{2}{*}{ Day 2} & Blood lactate & 1.663 & 1.3818 & 0.094 \\
\hline & $\mathrm{SvO}_{2}$ & 59.168 & 61.427 & 0.320 \\
\hline
\end{tabular}

ICU—Intensive care unit; $\mathrm{SvO}_{2}$ —Mixed venous oxygen saturation; $\mathrm{p}$ value $<0.05$ is significant. 
and intensive care unit stay. Duration of intensive care unit stay was higher (3.62 days) and statistically significant in serum creatinine $\leq 1.5 \mathrm{mg} / \mathrm{dl}$ group $(\mathrm{p}=0.001)$ (Table 6$)$.

\section{Discussion}

Blood lactate levels were measured as a means of evaluating tissue hypoxia. While it is not specific for oxidative damage during reperfusion, it may reflect the transition from anaerobic to aerobic myocardial metabolism [3]. Persistent lactate production after reperfusion reflects delayed recovery of aerobic metabolism. Postoperative hyperlactatemia has been shown to correlate with increased postoperative morbidity [4]-[6]. Off pump coronary artery bypass grafting although is associated with some risk of ischemia, definitive cell damage has not occurred as glycerol levels, a commonly accepted indicator of cellular membrane damage, do not increase overtime [7]. Factors independently associated with hyperlactatemia were the preoperative serum creatinine value, active endocarditis, duration of cardiopulmonary bypass, ionotropes and the peak blood glucose level [8].

Hyperlactatemia is of 2 types. Type A hyperlactatemia is due to impaired oxygen delivery to the tissues leading to anaerobic metabolism and excessive production of pyruvate which is converted to lactate. Type B hyperlactatemia represents the inability of peripheral tissue to use oxygen and not because of tissue dysoxia. A number of factors influence the production of lactate. Lactate concentration depends on the balance between production and elimination (by the liver). However, the kinetics of lactate clearance depends basically on the production rate, because hepatic clearance appears to be preserved even during cardiogenic shock [9]. A change in lactate level of $>3 \mathrm{mmol} / \mathrm{l}$ had the optimal sensitivity (82\%) and specificity (80\%) for mortality, although the positive predictive value was low [10]. After cardiac surgery, epinephrine and hyperglycemia were identified by Raper et al. [11] as factors frequently associated with a lactate concentration $>5 \mathrm{mmol} / \mathrm{l}$, but no statistical analysis was performed. Enhanced endogenous glucose levels have been described in cardiac surgery patients and are attributed to endogenous secretion of stress hormone and cytokine leading to insulin resistance, which can affect blood lactate levels [12]. Blood lactate values are measured as they can reflect morbidity in these patients. Lactate value of $3 \mathrm{mmol} / \mathrm{l}$ is taken as cutoff value and divided the patients into 2 groups, blood lactate $>3 \mathrm{mmol} / \mathrm{l}$ and blood lactate $\leq 3 \mathrm{mmol} / \mathrm{l}$.

Table 5. Comparison of outcomes in terms of duration of ventilation and intensive care unit stay in patients with blood lactate level $>3$ and $\leq 3 \mathrm{mmol} / \mathrm{l}$ and with mixed venous oxygen saturation $>65 \%$ and $\leq 65 \%$.

\begin{tabular}{cccccc}
\hline ICU Admission & Number & Duration of ventilation (days) & p value & Duration of ICU stay (days) & $p$ value \\
\hline Lactate $\leq 3$ & 24 & 1.0833 & 0.162 & 3.5417 & 0.666 \\
Lactate $>3$ & 6 & 1.0000 & & 3.6667 & $0.029 *$ \\
$\mathrm{SvO}_{2} \leq 65 \%$ & 8 & 1.1250 & 0.457 & 4.1250 & 3.3636 \\
$\mathrm{SvO}_{2}>65 \%$ & 22 & 1.0455 & & \\
\hline
\end{tabular}

ICU—Intensive care unit; $\mathrm{Svo}_{2}$ —Mixed venous oxygen saturation; *p value $<0.05$ is significant.

Table 6. Comparison of duration of ventilation and intensive care unit stay in different groups of patients.

\begin{tabular}{ccccc}
\hline & Duration of ventilation (days) & & Duration of ICU stay (days) & p value \\
\hline With left main & 1.00 & 0.51 & 3.27 & 0.185 \\
Without left main & 1.10 & & 3.736 & 0.611 \\
$\mathrm{EF} \leq 45 \%$ & 1.083 & 0.775 & 3.666 & 3.500 \\
$\mathrm{EF}>45 \%$ & 1.055 & 0.161 & 3.000 & $0.001^{*}$ \\
Creatinine $>1.5 \mathrm{mg} / \mathrm{dl}$ & 1.00 & & 3.629 & 3.454 \\
Creatinine $\leq 1.5 \mathrm{mg} / \mathrm{dl}$ & 1.074 & 0.163 & 3.631 & 0.533 \\
Number of grafts $>3$ & 1.000 & & \\
\hline
\end{tabular}

ICU—Intensive care unit; EF-Ejection fraction; *p value $<0.05$ is significant. 
The extent of hemodynamic compromise during cardiac surgery reflects the complications which can occur postoperatively, can be estimated by measuring mixed venous oxygen saturation (SvO2). It is shown that the value of mixed venous oxygen saturation on admitting to intensive care unit after surgery influences the short and long-term outcomes in cardiac patients. Since postoperative complications remain an important determinant of long-term outcome, we also wanted to study mixed venous oxygen saturation with regard to duration of ventilation and intensive care unit stay. In a study done by J. Holm et al. [13] it was shown that the best cut-off for 30 day mortality related to heart failure was mixed venous oxygen saturation $<60.1 \%$ with a sensitivity of $59.3 \%$, and a specificity of $82.4 \%$. The negative predictive value was $99.5 \%$. Postoperative morbidity was also significantly higher in patients with mixed venous oxygen saturation $<60 \%$ including higher incidence of perioperative myocardial infarction, renal failure, stroke, reoperation or bleeding, prolonged intensive care unit stay and ventilator hours. Thus in our study we have taken the lower limit of normal mixed venous oxygen saturation (65\%) as cut off value and to assess the outcome and divided the patients into 2 groups, mixed venous oxygen saturation $\leq 65 \%$ and $>65 \%$.

In a study done by Marco Ranucci [14] on pediatric patients undergoing cardiac surgery on cardiopulmonary bypass, results revealed that measuring central venous oxygen saturation alone has high predictive value for morbidity but not mortality. Combining blood lactate measurement along with central venous oxygen saturation has high sensitivity and specificity in predicting mortality and morbidity [15]. We have measured both blood lactate and mixed venous oxygen saturation in our study, mixed venous saturation being more specific than blood lactate. The blood lactate values of patients in all the groups are seen to increase from baseline till ICU admission, following which they showed a decreasing trend on day 1 and day 2 (Figure 1). In patients with creatinine $>1.5 \mathrm{mg} / \mathrm{dl}$ there was a significant increase in blood lactate level after grafting. The mixed venous oxygen saturation values decreased from baseline post operatively in all groups of patients (Figure 2). This can be attributed to the increase demand and oxygen extraction.

Duration of ventilation and intensive care unit stay also depends on other factors like age, cardiac function preoperatively, comorbid condition and severity of disease. We studied the involvement of left main artery, creatinine value, ejection fraction and number of grafts on outcome of patients (Table 6). The mean duration of intensive care unit stay was less in patients with creatinine $>1.5 \mathrm{mg} / \mathrm{dl}$. This finding might be due to other factors influencing the stay in intensive care unit like age and ejection fraction are relatively better in these patients than those with creatinine $\leq 1.5 \mathrm{mg} / \mathrm{dl}$. Another factor may is the disparity in number of patients among creatinine group. Majority of patients included in the study had good renal function that is creatinine $\leq 1.5 \mathrm{mg} / \mathrm{dl}$ and the blood lactate and mixed venous oxygen saturation are within normal limits.

Blood lactate

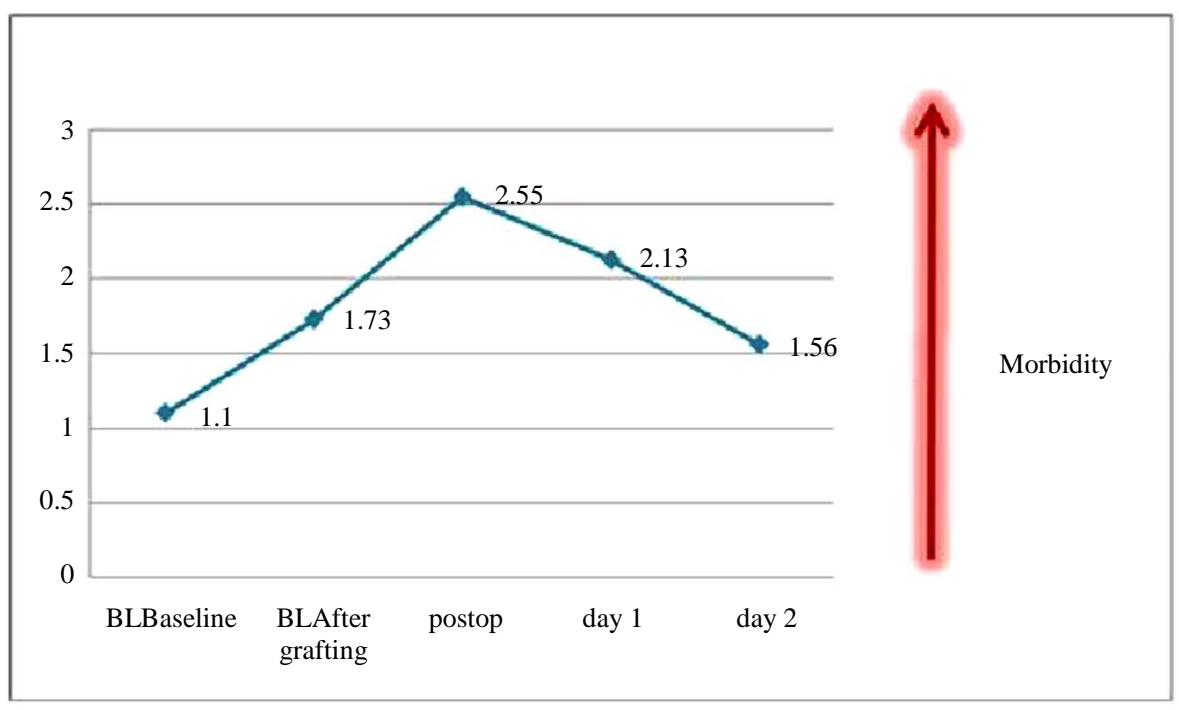

Figure 1. Line diagram showing the trend of blood lactate level. x-axis measuring blood lactate values in mmol/l. Values measured as mean. As blood lactate value increases morbidity increases. 
Mixed venous blood oxygen saturation

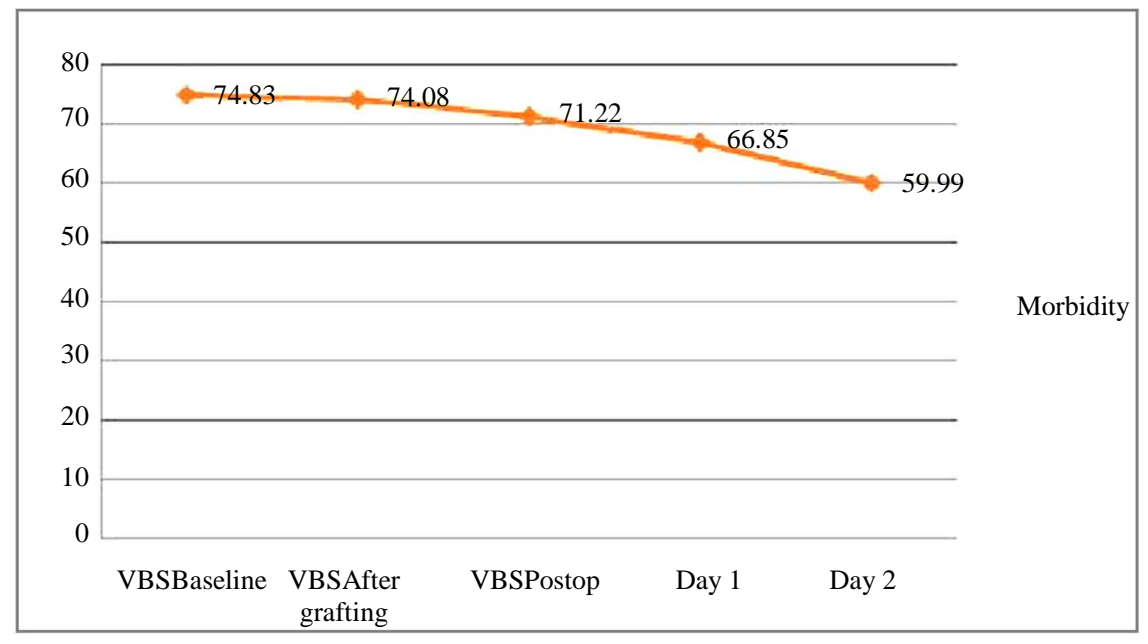

Figure 2. Line diagram showing the trend of mixed venous oxygen saturation. $\mathrm{x}$-axis measuring venous blood oxygen saturation in \%. Values measured as mean. As saturation increases morbidity decreases.

\section{Conclusion}

Monitoring the blood lactate and mixed venous oxygen saturation together in patients undergoing off-pump coronary artery bypass grafting has high sensitivity and specificity in predicting the outcome. However mixed venous oxygen saturation is more predictable than blood lactate in terms of duration of intensive care unit stay but not duration of ventilation. Early detection of abnormal values and prompt management will improve the outcome of the patients which influence the postoperative morbidity and thereby mortality.

\section{References}

[1] Fiaccadori, E., Vezzani, A. and Coffrini, E. (1989) Cell Metabolism in Patients Undergoing Major Valvular Heart Surgery: Relationship with Intra and Postoperative Hemodynamics, Oxygen Transport and Oxygen Utilization Patterns. Critical Care Medicine, 17, 1286-1292.

[2] Cavalca, V., Sisillo, E., Veliga, F. and Tremoli, E. (2006) Isoprostanes and Oxidative Stress in Off-Pump and OnPump Coronary Bypass Surgery. Annals of Thoracic Surgery, 81, 562-567.

http://dx.doi.org/10.1016/j.athoracsur.2005.08.019

[3] Rao, V., Ivanov, J. and Weisel, R.D. (2001) Lactate Release during Reperfusion Predicts Low Cardiac Output Syndrome after Coronary Artery Bypass Surgery. Annals of Thoracic Surgery, 71, 1925-1930. http://dx.doi.org/10.1016/S0003-4975(01)02634-0

[4] Yurvati, O., Blair, J.L. and Naig, M. (2003) Pyruvate Enhanced Cardioprotection during Surgery with Cardiopulmonary Bypass. Journal of Cardiothoracic and Vascular Anesthesia, 17, 715-720. http://dx.doi.org/10.1053/j.jvca.2003.09.007

[5] Abramson, D, Scalea, T.M. and Hitchcock, R. (1993) Lactate Clearance and Survival Following Injury. Journal of Trauma, 35, 584-588. http://dx.doi.org/10.1097/00005373-199310000-00014

[6] Mirmohammad-Sadeghi, M., Etesampour, A. and Gharipour, M. (2008) Relationship between Serum Lactate Levels and Morbidity Outcomes in Cardiovascular Patients after CABG. Journal of Surgery Pakistan (International), 13, 8891.

[7] Cossu, A.P., Suelzu, S., Piu, P., et al. (2012) Do On and Off Pump Coronary Artery Bypass Surgery Differently Affect Perioperative Peripheral Tissue Metabolism? Minerva Anesthesiology, 78, 26-33.

[8] Ranucci, M., De Toffol, B. and Isgrò, G. (2006) Hyperlactatemia during Cardiopulmonary Bypass: Determinants and Impact on Postoperative Outcome. Critical Care, 10, R167. http://dx.doi.org/10.1186/cc5113

[9] Chioléro, R.L., Revelly, J.P., Leverve, X., Gersbach, P., Cayeux, M.C., Berger, M.M. and Tappy, L. (2000) Effects of Cardiogenic Shock on Lactate and Glucose Metabolism after Heart Surgery. Critical Care Medicine, 28, 3784-3791. http://dx.doi.org/10.1097/00003246-200012000-00002 
[10] Munoz, R., Laussen, P.C., Palacio, G., Zienko, L., Piercey, G. and Wessel, D.L. (2000) Changes in Whole Blood Lactate Levels during Cardiopulmonary Bypass for Surgery for Congenital Cardiac Disease: An Early Indicator of Morbidity and Mortality. The Journal of Thoracic and Cardiovascular Surgery, 119, 155-162. http://dx.doi.org/10.1016/S0022-5223(00)70231-5

[11] Raper, R.F., Cameron, G., Walker, D. and Bovey, C.J. (1997) Type B Lactic Acidosis Following Cardiopulmonary Bypass. Critical Care Medicine, 25, 46-51. http://dx.doi.org/10.1097/00003246-199701000-00011

[12] Nilsson, F., Ekroth, R. and Milocco, I. (1988) Splanchnic Glucose Balance and Insulin Resistance in the Early Postoperative Phase of Cardiac Surgery. Journal of Parenteral and Enteral Nutrition, 12, 574-578. http://dx.doi.org/10.1177/0148607188012006574

[13] Holm, J., Hakanson, E., Vanky, F. and Svedjeholm, R. (2011) Mixed Venous Oxygen Saturation Predicts Short- and Long-Term Outcome after Coronary artery Bypass Grafting Surgery: A Retrospective Cohort Analysis. British Journal of Anaesthesia, 107, 344-350. http://dx.doi.org/10.1093/bja/aer166

[14] Ranucci, M., Isgrò, G., Carlucci, C. and De La Torre, T. (2010) Central Venous Oxygen Saturation and Blood Lactate Levels during Cardiopulmonary Bypass Are Associated with Outcome after Pediatric Cardiac Surgery. Critical Care, 14, R149.

[15] Hu, B.Y., Laine, G.A., Wang, S. and Solis, R.T. (2012) Combined Central Venous Oxygen Saturation and Lactate as Markers of Occult Hypoperfusion and Outcome Following Cardiac Surgery. Journal of Cardiothoracic and Vascular Anesthesia, 26, 52-57. http://dx.doi.org/10.1053/j.jvca.2011.07.021 
Scientific Research Publishing (SCIRP) is one of the largest Open Access journal publishers. It is currently publishing more than 200 open access, online, peer-reviewed journals covering a wide range of academic disciplines. SCIRP serves the worldwide academic communities and contributes to the progress and application of science with its publication.

Other selected journals from SCIRP are listed as below. Submit your manuscript to us via either submit@scirp.org or Online Submission Portal.
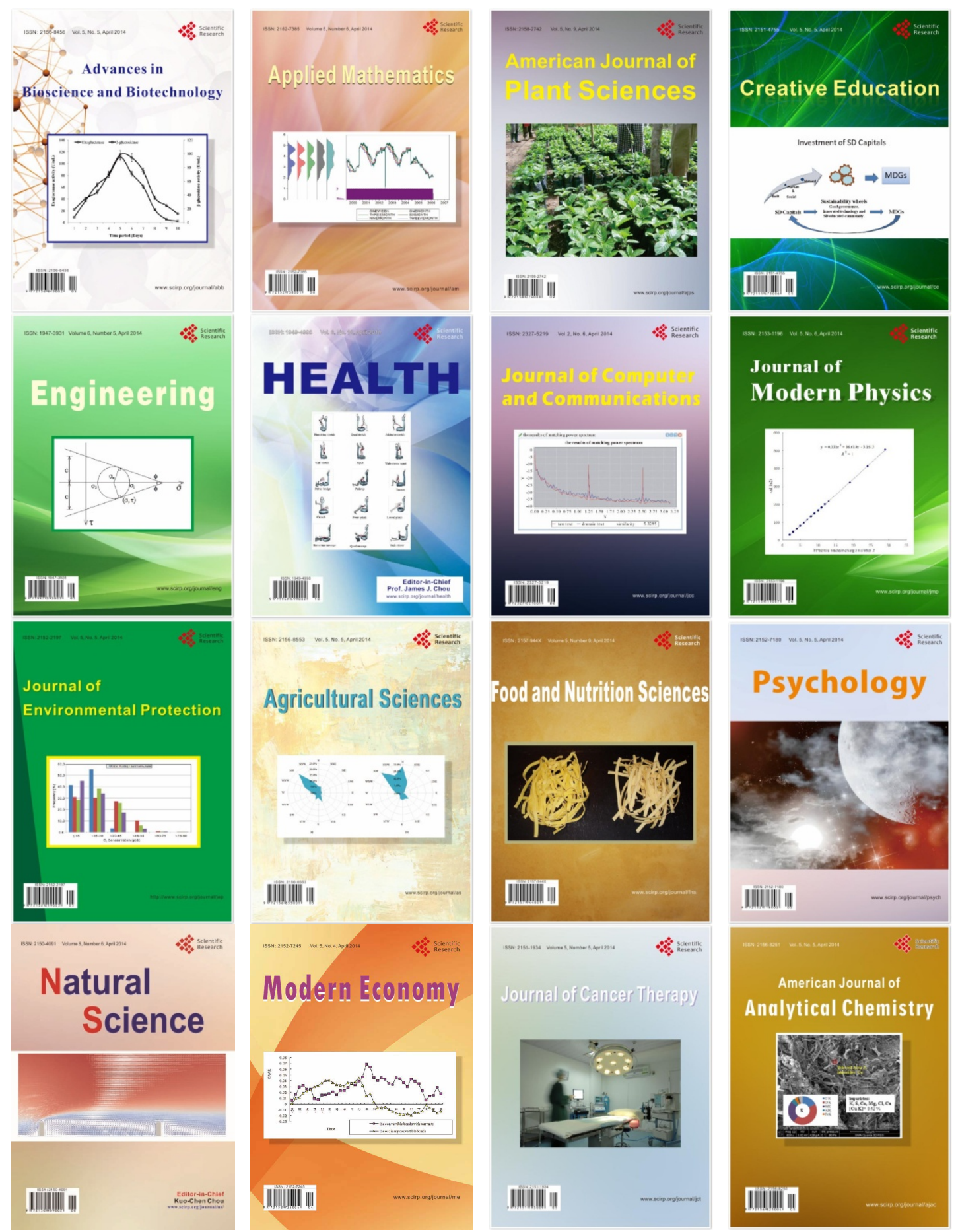